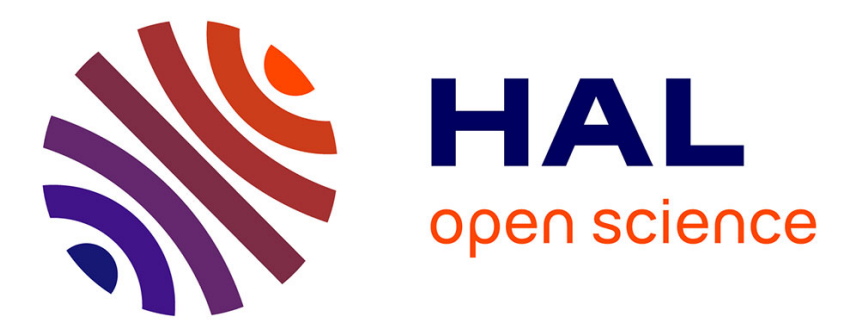

\title{
Towards the factory of future An integrated approach of material-processes-information-human being
}

Florent Laroche, Felipe Bordeu, Alain Bernard, Francisco Chinesta

\section{To cite this version:}

Florent Laroche, Felipe Bordeu, Alain Bernard, Francisco Chinesta. Towards the factory of future An integrated approach of material-processes-information-human being. ACM - Proceedings of the 2012 Virtual Reality International Conference, 2012, ISBN: 978-1-4503-1243-1; 6 p. 10.1145/2331714.2331730 . hal-00725770

\section{HAL Id: hal-00725770 \\ https://hal.science/hal-00725770}

Submitted on 28 Aug 2012

HAL is a multi-disciplinary open access archive for the deposit and dissemination of scientific research documents, whether they are published or not. The documents may come from teaching and research institutions in France or abroad, or from public or private research centers.
L'archive ouverte pluridisciplinaire HAL, est destinée au dépôt et à la diffusion de documents scientifiques de niveau recherche, publiés ou non, émanant des établissements d'enseignement et de recherche français ou étrangers, des laboratoires publics ou privés. 


\section{Towards the factory of future An integrated approach of material-processes- information-human being}

\author{
Florent LAROCHE \\ LUNAM Université, Ecole Centrale Nantes \\ IRCCYN UMR CNRS 6597 \\ 1, rue de la Noë, 44000 Nantes, France \\ florent.laroche@irccyn.ec-nantes.fr \\ Felipe BORDEU \\ LUNAM Université, Ecole Centrale Nantes \\ GeM UMR CNRS 6183 \\ 1, rue de la Noë, 44000 Nantes, France \\ felipe.bordeu@ec-nantes.fr
}

\author{
Alain BERNARD \\ LUNAM Université, Ecole Centrale Nantes \\ IRCCYN UMR CNRS 6597 \\ 1, rue de la Noë, 44000 Nantes, France \\ alain.bernard@irccyn.ec-nantes.fr \\ Francesco CHINESTA \\ LUNAM Université, Ecole Centrale Nantes \\ GeM UMR CNRS 6183 \\ 1, rue de la Noë, 44000 Nantes, France \\ francisco.chinesta@ec-nantes.fr
}

\begin{abstract}
This article deals with the propositon of a new generation of our industrial factories. The integration of the most resulting advanced techniques will lead to a change of paradigm in the definition of new efficient production systems. In this article, we develop the main ideas of the project ARTUR. The core is to build new and executable strategies for embedding both current and new simulation capabilities into factory material processing and product evaluation; thereby creating a human friendly "robotic" factory environment where online simulation can control both process and product performance in real-time.
\end{abstract}

\section{Categories and Subject Descriptors H.1.2 [User/Machine Systems]}

\section{General Terms}

Documentation, Performance, Design, Experimentation, Human Factors, Standardization, Languages.

\section{Keywords}

Factory, industrial engineering, PLM plateform, virtual assistant, augmented semantic reality.

Permission to make digital or hard copies of all or part of this work for personal or classroom use is granted without fee provided that copies are not made or distributed for profit or commercial advantage and that copies bear this notice and the full citation on the first page. To copy otherwise, or republish, to post on servers or to redistribute to lists, requires prior specific permission and/or a fee.

Laval Virtual VRIC '12, March 28-April 1, 2012, Laval, France.

Copyright 2012 ACM 978-1-4503-1243-1 ...\$10.00

\section{INTRODUCTION: WHY USING BIQUITOUS COMPUTING FOR INDUSTRIAL FACTORY?}

Nowadays, enterprises have acquired various tools that allow them to be very confident with the products they develop. The concept of smart factories proposes them to automate and to control most of their tasks. Thanks to sophisticated robots, they can increase their manufacturing capabilities. Industrial processes and scientific methods are so numerous that they can help them to imagine, design and manufacture incredible product. However, with such knowledge and know-how contained inside database, it is very difficult to find the good rule, more generally the good information, we are looking for, in order to take decision or to act on the product or service [1]. Main hypothesis of our research project team is that in few years we will be able to provide new concept for helping industrial jobs by letting any people in the company access to the relevant information in the right situation in the right way, through adequate interfaces and devices.

For office jobs, software provides multiple assistants for helping people to work. Those "companions" are in fact simple dictionary with good lexicons. However, when dealing with technical and scientific objects and contexts, it is more difficult to provide such assistant. Our proposition is to create a new "companion" (assistant) that will assist engineering phases. Thanks to a coupling to a knowledge base, the system will automatically help the user to do its job better than before [2].

Our proposition is to develop a customable company assistant that will be based on possible interaction with complete information set and different decision aided functionalities, through Virtual Technologies techniques. This will allow to extend the dimensions of Virtual Technologies models with further data sets. There will be the development of a framework with which the access to CAX models (Computer Aided Design/Manufacturing/...), Product Lifecycle Management information (PLM), material flows, process chains, simulation 
data and Enterprise Resources Planning data (ERP) may be possible [3].

As explained by Satyanarayanan and adapted by Ray, our Society have progressively moved from a Distributed System to a pervasive and ambient computing [4]. The first two states have been observed but the last and third one is arriving [5]. We can distinguish them by their characteristics:

\section{Distributed Systems:}

- Remote access to information: distributed file systems, databases, caching and synchronization mechanisms...

- Security and availability: encryption, authentication, backup...

- Remote communication: network protocols, transmission technologies, client/server model...

- Fault tolerance: frames control, consistency, replication and migration, behavior and fail-stop model...

2. Mobile Systems:

- Uses and topologies: ballad, transportation, tour, transitions between areas, heterogeneous population...

- Mobile networks: dynamic topology, continuity of service, roaming, heterogeneity, reliability, security, latency...

- Mobile client platforms: mobility, integration, summarized interfaces, limited resources, dynamic environment...

3. Ubiquitous systems:

- Context measurement: location, activities sensors, interactions measures...

- Personalization: user profiles, indicators of interest, collaborative filtering, contextual annotation...

- Adaptation: filtering in function of the use, interface degradation, migration platform...

Indeed, factories are changing their way of working like people in daily life are changing their way of living. If we compare "ordinary life" and "factory life", we can observe there is a gap between both. Usually, people have better computers at home than at offices. Moreover, they use their mobile phone and world wide access everytime. Due to their robustness, industries are, most of the time, late and apart from these practices. Then, future of the factory must be attractive and demonstrate a great advance in the use of technologies (see figure 1).

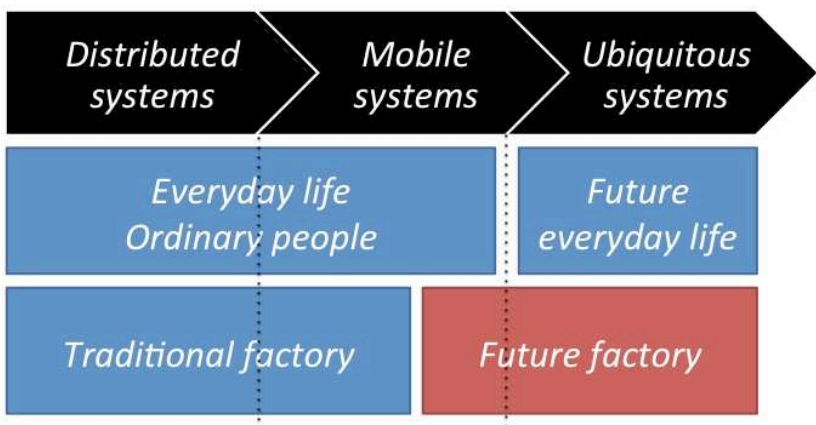

Figure 1. From distributed systems to ubiquitous systems: everydaylife VS factory

Consequently, the term ubiquitous computing [6] introduce in 1991 by Weiser for describing a computer vision where it provides help services without anyone noticing its presence can also bring better optimization if applied to industries. We must remind that researches about pervasive and ambient computing [7] appeared in the mid-90s thanks to industrial projects. Mainly promoted by IBM, the company has since focused on technical aspects including the development of media software and hardware needed to realize the vision of Weiser.

This article will explain our main hypothesis of the factory of the future. In the first part of this article, we will present the problem of traditional factory demonstrating that there is a lack in the present way of working. Then, we describe our global proposal and our scientific contributions. Finally, we will discuss and conclude.

\section{SYSTEM STATEMENT: THE TRADITIONAL FACTORY}

Traditional factories can be pictured as black boxes operating on materials (inputs) to produce parts (outputs); the black box consisting mainly of manufacturing processes. However, many processing constraints have to be taken into account in order to fulfill the important requirements of manufactured parts. Thus, careful thought needs to be given to the materials and the process. This is the manner by which natural feedback acting on materials and processes was introduced to manufacturing activities many years ago.

However, the traditional approach seems to be too limited 9 reasons.

\subsection{The subtle coupling between materials, processes and products}

The behavior of materials is strongly dependent on the forming process itself and consequently on the properties of manufactured parts. If this assertion applies for any kind of material, it is especially restrictive in the case of composite materials that do not exist "a priori", because it is precisely the forming processes that create them. Thus, nowadays, materials, processes and manufactured products can no longer be considered separately, their interdependency is incredibly strong.

\subsection{When classical process control becomes insufficient}

Online material and process control and optimization are carried out by considering different approaches. The most common approach consists, as described above, in considering the manufacturing process as a black box whose behavior is modeled by a transfer function relating certain inputs (concerning the material and process) to certain outputs (generally related to the quality of manufactured parts or productivity). This modeling may seem poor. The advantage is that it can be performed rapidly due to its simplicity. This compromise between accuracy and rapidity was often used in the past and this pragmatic approach has allowed us to control processes and to optimize them, once the transfer function modeling the system is established. The establishment of such goal oriented transfer function is the trickiest point. For this purpose, it is possible to proceed from a sometimes overly simplified physical model or directly from experiments (allowing us to extract a phenomenological goal oriented transfer function) or from a well-balanced mixture of both approaches. In all cases, the resulting modeling can only be applied within the framework that served to derive it. The multiscale description of materials, processes and structures and their couplings usually requires a sufficiently detailed description of 
them and, in that case, traditional goal oriented simplified modeling becomes inapplicable and manufacturing processes are confronted by their limits.

\subsection{When numerical simulation becomes too expensive}

When considering the physical modeling of materials, processes and structures, all of them result in complex mathematical objects, non-linear and strongly coupled partial differential equations. Such mathematical objects are supposed to represent physical reality up to a certain degree of accuracy. However, the numerical tools capable of solving these complex models require the use of powerful computers that can require hours, days and weeks to solve them. Known as numerical simulation, its output solution is very rich but it seems inapplicable for control purposes that require fast responses, often in real-time. Until now, numerical simulation has been used offline but in some cases it allows us to define simplified models (with their inherent limitations and drawbacks) running in real-time that could be used online but such simplified modeling has the previously quoted drawbacks.

\subsection{Issues of optimization and inverse methods}

Optimization and inverse methods require the solution of many problems, each one related to the selection of trial design parameters. These parameters concern the three main ingredients of manufacturing systems: materials, processes and parts. The first ingredient is addressed in the framework of computational materials whereas the last one constitutes structural mechanics (including damage and failure analysis). Both of them are affected by the current limitations of numerical modeling and mainly by the computing time needed for performing standard optimization procedures.

\subsection{Using cybernetic: The colonization of robots}

Robots colonized factories many years ago but they suffer from two main limitations. Their control is carried out from material and structural models that are simple and process models that imply an excessively low degree of freedom and their architecture does not allow for new challenges, such as producing very large structures. They don't seem to be well adapted to next generation factories. Bio-inspired robots could open numerous avenues but their introduction to production systems requires further development in many related fields. For example, autonomous operation requires efficient advanced control strategies, some of them based on finely detailed data simulation coming from haptic devices, images and sound. This simulation must be accurate enough and run in real-time.

\subsection{Distancing R\&D}

R\&D is too far from production activity, the machines and the employees that supervise the conformity of its function. In some malfunctioning scenarios, the employer needs to make quick decisions (without requiring the intervention of the $R \& D$ department) despite being a non-specialist.

\subsection{The recurring dream of producing quickly and cheaply}

The factory, like every component of our society, is faced with a new and very rigid constraint: producing quickly and cheaply. In the context of production systems, one needs to treat reality (not an overly simplified vision of it) considered globally (the whole system with all its couplings and interconnections), as fast as possible (real-time is compulsory in some applications) and by using, if possible, devices that are as light as possible, facilitating their use by non-specialists and their introduction into embedded platforms making use of the most recent breakthroughs such as augmented reality on handheld devices. Obviously these possibilities and facilities do not exclude traditional aspects that cannot be circumvented in certain applications, in particular, in complex structural analysis, when the models to be used sometimes remain under construction.

\subsection{The obscure destiny of knowledge}

It is highly regrettable that existing knowledge within the factory, that has resulted from wide experience, from the studies realized internally or externally and so forth, is yellowing in the racks of an obscure room, lost somewhere in the factory. New storage and management of existing information and knowledge is urgently needed.

\subsection{The human being abused by the factory environment}

Interaction between the human being and the machines or environment is a topic that is often underestimated. More satisfactory relations need to take the psychological aspects into account and also improve the factory environment by controlling many factors, the noise being one of the most important. The relations between human beings, machines, robots and their environment must play a central role in production systems.

\section{PROJECT AND ACTIONS}

Those previous items summarize the present state of the art in manufacturing systems, independently of their size: a parceled approach that is inefficient and unsatisfactory from all points of view. The research project should overcome these main drawbacks allowing for the achievement of the numerous objectives.

Obviously, there are numerous scientific breakthroughs to be achieved in each of the four main components of a production system: materials, processes, parts and systems. Models of processes, materials in processing conditions and structures under functioning conditions currently exist or are under development. Introduction of these models into the framework of computer aided manufacturing and its link with machines, robots and information systems [8], taking uncertainty into account, require the use of highly efficient numerical simulation strategies, some of which are able to proceed online. All these developments should then be integrated into a new framework consisting of new generation factories.

The factory of the future will focus on two themes:

- The first theme is composed of eleven research projects, called BRICKS -B- that consists of three axes: processes $(\mathrm{P})$, products (Pr) and systems (S)

- The second theme, called WALL -W-, consists in the assembling of the bricks and constitutes the integrated concept of a factory.

The main output is the development of different demonstrators, some of them within virtual and augmented reality embedded platforms, to be tested in industrial environments. 
Table 1. The three bricks

\begin{tabular}{|c|c|c|}
\hline PROCESS bricks & PRODUCT bricks & SYSTEMS bricks \\
\hline $\begin{array}{l}\text { 1. Materials in processes. } \\
\text { Descriptions and image based simulation: } \\
\text { Search for the key materials properties } \\
\text { and process parameters affecting the } \\
\text { fabrication of parts, through multiscale } \\
\text { and multiphysics characterization and } \\
\text { modeling }\end{array}$ & $\begin{array}{l}\text { 1. Identifying defects - Non-destructive testing. } \\
\text { Emerging characterization methods of nonlinear } \\
\text { acoustics - Understanding fundamental processes } \\
\text { of nonlinear wave interactions with non-classical } \\
\text { nonlinearities for the development of } \\
\text { characterization methods in association with } \\
\text { dedicated signal processing and analysis in terms } \\
\text { of detection capability and structural reliability. }\end{array}$ & $\begin{array}{l}\text { 1. Human-machine interaction and } \\
\text { interfaces. } \\
\text { Taking human factors into account in } \\
\text { the design of control interfaces and the } \\
\text { supervision of process control. }\end{array}$ \\
\hline $\begin{array}{l}\text { 2. Technology of non-conventional } \\
\text { materials and processes: glasses, metals } \\
\text { and composites. } \\
\text { Accounting for localized multiphysics } \\
\text { involving an extremely large number of } \\
\text { process parameters for describing } \\
\text { complex and optimal process trajectories. }\end{array}$ & $\begin{array}{l}\text { 2. Modeling and simulating durability, damage } \\
\text { and failure. } \\
\text { Failure homogenization (from constituents to } \\
\text { material) and durability assessment (from } \\
\text { material to product). }\end{array}$ & $\begin{array}{l}\text { 2. Systems of information. } \\
\text { Model and structure of, interaction with } \\
\text { information factory assistant. } \\
\text { Computer-Aided decision making } \\
\text { based on context-based simulation and } \\
\text { performance evaluation of factory } \\
\text { processes. }\end{array}$ \\
\hline $\begin{array}{l}\text { 4. Production robotics and bio-inspired } \\
\text { robotics in the factory of the future. } \\
\text { Development of a new generation of } \\
\text { robotic systems for the factory of the } \\
\text { future. Designing robots, control and } \\
\text { sensing strategies to meet very high } \\
\text { performances. Bio-inspiration as an } \\
\text { approach to provide efficient locomotion } \\
\text { and sensing skills. }\end{array}$ & & $\begin{array}{l}\text { 4. Computational imaging. } \\
\text { Advanced information processing } \\
\text { techniques allowing for the production } \\
\text { of accurate images of unobservable } \\
\text { structures (e.g., inner parts of opaque } \\
\text { bodies) from indirect measurements. }\end{array}$ \\
\hline
\end{tabular}

The theme WALL constitutes the main output of the project. As mentioned above, different demonstrators and rational approaches will be developed, and they should be tested in the industrial framework in the R\&D departments (in large, medium and small industries). Some embedded platforms should be checked and evaluated by non-specialist employees involved in production systems. The feedback of this evaluation should allow for the improvement of approaches and tools until they reach the desired degree of satisfaction.

1. "Offline-Online" simulation and online control of a robotized process based on optimization and/or nondestructive testing: Application to composites tape placement, incremental forming, forming of functional composite laminates... (these processes have never until now been finely simulated and controlled in real-time based on process and product outputs). Participating bricks: Process 1/2/3/4, Product 1/2/3, System 3/4

2. Augmented reality embedded system "Companion or Avatar" for helping employee to make decisions for controlling processes, in real-time, based on "offlineonline" simulation, information systems and machinehuman interaction. Application to control of woven, autoclaves, and many other production systems... Participating bricks: Process $1 / 2 / 3 / 4$, Product 2, System $1 / 2 / 3$

The first wall is related to mechanical and simulation domain. We will not develop it in this article as it does not fit with the topic of VRIC conference. In the next part of this communication, we will develop the $2^{\text {nd }}$ wall consisting to design an intelligent information system for assisting industrial people daily works.

\section{TOWARD A DIGITAL FACTORY ASSISTANT}

Enterprise knowledge is one of the most important factors for enterprise competitiveness [9]. In the context of a real knowledgebased factory of the future, which is coherent with the "digital factories" issues of the "IC-enabled Intelligent Manufacturing" topic of the Strategic multi-annual roadmap of the Factories of the Futures PPP [10], one of the main challenges is to let anyone in the factory access and reuse a customized knowledge set at any time depending on his/her role and tasks. In addition of what 
already exists [11], there is a need for new information systems and for new knowledge customization mechanisms to achieve these goals. At all times, each person in the company has a role and needs to access and to interact with the right information at the right time, in the right place, for each given working situation.

But accessing given information is not sufficient. What is innovative is to be able to contextualize the right set of information, to combine pieces of knowledge and to use performance evaluation tools (in particular simulation) in order to provide relevant information for decision making.

For example we can imagine that a mechanical designer is creating a machine for printing dates on eggs (it is a real situation). Indeed, for safety reason of French food control, it is an obligation to print the date on it. The principle is simple but the action is very difficult because eggs are fragile pieces. When the buffer will hit the egg, it has to do it carefully otherwise the buffer will destroy the egg. The factory assistant will then help the designer to identify all the design constraints surrounding this problem. Next, it will propose him some solutions and some requirements for its design. For example, it can propose some similar products like old printing machine. Those machines were used to print books or posters. But to draw some clear drawings, they required a high precision. Indeed, they have the same principles as the printing machine for eggs. Thanks to this similar technology, the digital assistant will drive the designer for its job.

Foundations of our research project relate to a new proposition for modeling and structuring information, and more generally knowledge. Consequently, dealing with the global data, information, knowledge and know-how, we will be able to contextualize reusing this knowledge in any given situation that would need this knowledge. The basic concept is the one of the so-called "digital factory assistant", based on a complete customized information environment. To achieve this goal, each person in the company will have to define the structure and the organization of his/her personal knowledge book. The mechanisms will be the ones of the so-called "ezoombook", based on the possibility to aggregate a great deal of different modular information and knowledge but this will not be static, this will evolve depending on the role, the experience, the needs and the maturity level of each person in the company. The basic idea is to allow each person to be able to react in a given situation, mainly thanks to high speed simulation and performance evaluation models and methods.

New devices and new ways of interaction will also have to be defined and developed because of the complexity of some working situations. The main issue is to propose an innovative framework and a global methodology for the interactive reuse of knowledge and for the interactive use of performance evaluation systems in each given working situation in the factory. The scientific proposition will be based on enterprise object models, like FBS-PPRE [12], associated to general frameworks based on SOA [13][14] and ubiquitous service environments approaches [15]. Knowledge-based multi-agent systems will be exploited and connected to optimization approaches in accordance with the needs of rapid feedback to the user [16].

In a given working situation the challenge will be to deliver relevant information to the person in a shorter time compared to the real process evolution. This will allow a better reactivity and a more efficient access to former experience feedback. There are several complexity factors: the diversity of products and processes, the diversity of working situations, the quantity of models, of knowledge, of simulation and performance evaluation systems, multi-physics problems to be solved, multi-objective problems to be optimized. This corresponds to one of the main issues for a real integrated factory of the future, as defined in ManuFuture objectives [17]. By extension, due to the intelligent characteristics of the virtual assistant, we now speak about learning factory for the future.

\section{CONCLUSION AND PERSPECTIVES}

For designing this information factory assistant, we need to create interactions between models and structures of the factories. This virtual assistant will help industrial people for their daily works by giving them computer-aided decision making [2]; in order to achieve that, the assistant will computes thanks to context-based simulation and performance evaluation of the factory processes.

Due to the amount of technologies and applications, it required each time a one shot methodology. Our goal is to provide a common centered core model that will be useful and applied for any material, process or product: furnishing a global response to global needs. Consequently, the system will be effectiveness for any SMBs. To this effect, the progress could, in the long run, give a headstart to industries in terms of innovative efficiency in production systems in a wider sense.

\section{ACKNOWLEDGMENTS}

Due to the inter-disciplinarity of the project, involved laboratories are following. The bringing together of our skills will allow us to go beyond the simple juxtaposition of skills so that a new competence will emerge.

- GeM, Institut de Recherche en Génie Civil et Mécanique, Nantes, France, UMR CNRS 6183

- IRCCyN, Institut de Recherche en Communication et Cybernétique de Nantes, France, UMR CNRS 6597

- $\quad$ CERMA, IRSTV, UMR CNRS 1563, Nantes France

- CRINI, Université de Nantes, France

- LTN, UMR 6607, Université de Nantes, France

- CLARTE, Virtual reality and augmented realty technologic transfer support platform, Laval, France

Involved laboratories took place in a singular environment centered around Technocampus $\mathrm{EMC}^{2}$ in Nantes (France). We would like to kindly thank our sponsor for Artur project: the "region Pays de la Loire". More information and future results are promoted here: www.future-factory.org

\section{REFERENCES}

[1] Noël \& al, 2012, Deliverable D11.7: Meta-modelisation of the usage and assessment of visualization and interaction processes, FP7 VISIONAIR Project, www.infra-visionair.eu

[2] H. Kuehnle, U. Bergmann, A. Lüder, 2009, Design of MultiAgent Decision Support for Configurations of Manufacturing Networks, ICE international conference, Leiben, 7 p., www.ice-conference.org

[3] J. Le Duigou, A. Bernard, N. Perry, J.-C. Delplace, 2008, Inductive approach for the specification of a generic PLM system in an extended enterprise context, proceedings of the $5^{\text {th }}$ international conference on Digital Enterprise Technology 
[4] Satyanarayanan, 2001, Pervasive Computing: Vision and Challenges, IEEE Personal Communications

[5] G. Cliquet, 2010, Méthode d'innovation à l'ère du Web 2.0, phD thesis, Arts-et-Métiers Paris Tech, 155 p.

[6] K. Lyytinen and Y. Yoo, 2002, Issues and challenges in ubiquitous computing, special issue: Issues and challenges inubiquitous computing 45(12)

[7] Syvanen, R. Beale, 2005, Supporting Pervasive Learning Environments: Adaptability and Context Awareness in Mobile Learning, Proceedings of the IEEE International Workshop on Wireless and Mobile Technologies in Education, IEEE Computer Society

[8] B. Vallespir, V. Chapurlat, 2007, Enterprise modelling and verification approach for characterizing and checking organizational interoperability, $12^{\text {th }}$ IEEE Conference on Emerging Technologies and Factory Automation, Vol. 1-3, pp. 839-846

[9] L.T. Ndlela, 2001, Establishing a knowledge management programme for competitive advantage in an enterprise, International Journal of Information Management, Volume 21, Issue 2, Pages 151-165

[10] Ad-hoc advisory group of Factories of the Future PPP, 2010, "digital factories" issues of the "IC-enabled Intelligent Manufacturing" topic of the Strategic multi-annual roadmap of the Factories of the Futures PPP, pp 12-14, http://www.manufuture.org/manufacturing/wpcontent/uploads/FoF_PPP_Roadmap_Final_Version.pdf
[11] A. Bernard, S. Tichkiewitch (Eds.), 2008, Methods and Tools for Effective Knowledge Life-Cycle-Management, 586 p., Hardcover, Ed. Springer, ISBN: 978-3-540-78430-2, DOI : 10.1007/978-3-540-78431-9_1

[12] M. Labrousse, A. Bernard, P. Véron, 2004, Generic FBS concept for Process/Product/Resource integration, in Tools and Methods of Competitive Engineering, Edited by Imre Horwvath, Paul Xirouchakis, Volume 1, pp.383-394, Millpress Rotterdam Netherlands, ISBN 90-5966-018-8

[13] T. Erl, 2005, Service-Oriented Architecture: Concepts, technologies and design, Chapter 16, Library of Congress Number: 2005925019, Person Education Inc., ISBN 0-13185858-0

[14] N. Komoda, 2006, Service-Oriented Architecture (SOA) in Industrial systems, IEEE International Conference on Industrial Informatics, pp 1-5, ISBN: 0-7803-9700-2, DOI: 10.1109/INDIN.2006.275708

[15] P. Werle, F. Kilander, M. Jonsson, P. Lönnqvist, C. G. Jansson, 2001, A ubiquitous service environment with active documents for teamwork support, Lecture notes in computer science, vol. 2201, pp. 139-155, ISSN 0302-9743

[16] Priti Srinivas Sajja, 2008, Multi-Agent System for Knowledge-Based Access to Distributed Databases, Interdisciplinary Journal of Information, Knowledge, and Management, Volume 3, pp. 2-9

[17] ManuFuture platform, 2011, http://www.manufuture.org/manufacturing/ 